\title{
How Sustainable is the Smart Farm?
}

\author{
Adam Streed \\ Institute for Digital Agriculture \\ adam.streed@digitalaginstitute.org \\ Bill Tomlinson \\ UC Irvine \\ wmt@uci.edu
}

\author{
Michael Kantar \\ University of Hawaii \\ mbkantar@hawaii.edu
Barath Raghavan
USC \\ barathra@usc.edu
}

\begin{abstract}
Computer-controlled hydroponics, vertical farms, and IoT-based precision agriculture are claimed to be sustainable, healthful, and humane methods of producing food. These so-called "smart" farming methods have arisen over the past decade and have received little scrutiny from a sustainability perspective. Meanwhile, they are attracting vast sums of both research and investment funding.

We ask a simple question: how sustainable is the "smart farm"? We take a technical, ecological, and social view of the systems that comprise a smart farm. Our aim is to tease apart which, if any, of the practices are actually beneficial, and which are simply a substitution of resources or a mere shifting of (human and/or ecological) externalities in time or space. To evaluate the smart farm concept, we focus on two scenarios: indoor smart farms (controlledenvironment agriculture such as vertical farms), and outdoor smart farms (in which the environment is less controlled, but managed via precision agriculture). We also provide examples of the values that smart farms embody, who stands to gain from their operation, and what better alternatives might exist.
\end{abstract}

\section{KEYWORDS}

sustainability, smart farms, vertical farms, digital agriculture

\section{Reference Format:}

Adam Streed, Michael Kantar, Bill Tomlinson, and Barath Raghavan. 2021. How Sustainable is the Smart Farm?. In LIMITS '21: Workshop on Computing within Limits, June 14-15, 2021.

\section{INTRODUCTION}

Over the past decade, as computing has permeated nearly all aspects of modern society (e.g., transportation, health and medicine, and human interaction), many people and organizations have proposed to leverage computing to improve the sustainability and productivity of agriculture. As human population continues to grow in the face of two large and intertwined problems-climate change and fossil fuel depletion-the food system has become a locus of serious concern. How can we feed still more people while using fewer resources and producing less pollution?

In recent years, the so-called smart farm has gained attention. More an umbrella concept than any particular farm plan, the smart

Permission to make digital or hard copies of part or all of this work for personal or classroom use is granted without fee provided that copies are not made or distributed for profit or commercial advantage and that copies bear this notice and the full citation on the first page. Copyrights for third-party components of this work must be honored. For all other uses, contact the owner/author(s).

LIMITS '21, fune 14-15, 2021,

(C) 2021 Copyright held by the owner/author(s). farm promises to meet food production goals sustainably by employing recent advances in computing technology (particularly robotics, sensing and actuation hardware, and networking) to run largely-automated agricultural operations with unprecedented, superhuman efficiency.

There is, no doubt, a need to replace today's industrial agriculture. Extant high-input monocultural crop systems are largely grown using high-intensity management practices [22]. While highly productive, global ecological change makes it unlikely that these practices will persist as they continue to deplete natural resources and struggle with the emergence of new pests and pathogens that threaten food security.

However the alternative smart-farming approach has an enormous, unexamined footprint: the energy and resources used by smart farming technologies themselves. While purveyors of indoor smart farms often claim to be "green" [1], citing for example the recycling of water in vertical farming systems [2], they fail to consider the whole picture. We consider that bigger picture, including the energy used by LEDs to grow crops, the cooling systems needed to manage indoor temperatures, and the hardware itself used in sensing and actuation. Such systems are used today to grow leafy greens, with grandiose claims about feeding the world [5]. We find, contrary to such claims, that these systems are not beginning with leafy greens but ending with them: more energy-intensive, caloriedense crops simply cannot be grown in this way while remaining energetically and economically efficient. And once all this hardware reaches the end of its life, it must be disposed, creating an e-waste footprint for each head of lettuce. In the outdoor setting, precision agriculture aims to employ similar technologies of sensing and actuation to improve upon existing unsustainable industrial agricultural methods. While this approach faces fewer of the fundamental energy flow constraints of vertical smart farms, its e-waste and embodied energy footprint is still vast, as we discuss later.

These smart farming systems are built upon general-purpose computing platforms; sensors transmit up-to-the-minute data to cloud servers; drones assess the health and productivity of crops; and tractors drive themselves along predefined routes. Yet, in both the creation and use of these computing technologies, technology designers and users rarely consider the implicit values that drive technologies creation and use, and subsequently amplify [41] an implicit design and value set. This means that the uses of computing seldom go beyond replacing the same tasks that have always been done by humans. Throughout agricultural history, farmers always sensed (observed) and then acted based upon what was taking place in their fields. Over the last century-and with smart farming to an 
even greater extent-electromechanical technologies are brought to bear to replace human labor.

More than their lack of long-term thinking (which leads to unsustainability and fragility), these approaches to smartness also fail to take into account the possibility that new technologies could be transformative in terms of both human agency and global wellbeing. Odom observed this a decade ago in early work on the application of new technologies to farms, and while the technologies have advanced, the perspectives they embody remained mired [23].

Assessing the smart farm's prospects with any exactness is difficult, precisely because its broad conception admits of indefinitely many concrete instantiations. Nonetheless, the popular conception appears to be a combination of the environmental control exemplified by technologies like the greenhouse, and the electromechanical sophistication of contemporary farm computing technologies (Figure 1). As such, we think that the approach is likely unsustainable and unscalable, and that its appearance of innovation and novelty is illusory. We hope that by laying out the considerations against the smart farm, we can lay a foundation for what it means to design genuinely sustainable farming for the future.

\section{DEFINING THE SMART FARM}

In today's popular discourse there is an assumed meaning to smart farm. If one were to attempt to define it, it would be by saying that the farm in question uses recent general-purpose computing technology. But once we dig deeper into what a smart farm entails, it quickly becomes apparent that what makes a smart farm a smart farm is that it is in rebellion against doing farming the "hard way". This is defined implicitly as the ways in which farming may have been done in the pre-industrial past.

In this section, we attempt to decompose the space of farming systems and of so-called smart farming systems to better understand what makes them different.

\subsection{Two Types of Agricultural Technology}

Agriculture has been an area of human technological innovation for thousands of years, and there is truly little new in recent systems. Indeed, even many of today's sustainable agricultural practices aim to re-discover complex systems of agriculture that had been practiced sustainably by traditional communities around the world. If we want to know what's new about the smart farm-what makes it smart by contrast with previous farming-we need to distinguish agricultural technologies along two dimensions.

One type of agricultural technology aims at controlling the growing environment. Weather is unpredictable, pests threaten to devour or spoil the harvest, weeds choke the crops, sunlight is intermittentin response to these and other environmental vagaries, human beings have developed technologies to achieve some level of control. The greenhouse is a relatively venerable example, but before plate glass was widely available, "fruit walls" enabled even northern European cities to grow fruit trees by trapping solar energy and releasing it at night, creating reliably warm microclimates [11]. The list of such control-oriented agricultural technologies is long and goes back millennia, including terraces (for controlling runoff), irrigation (precipitation), scarecrows and fences (pests), and plows and harrows (soil structure).
The second type of agricultural technology is much more recent, consisting of electromechanical devices that do the work of humans or other animals in establishing and managing a farm. Where once farmers had no choice but to wield shovels or yoke draft animals to plows, the 19th and 20th centuries saw the application of internal combustion, precision machining, and-more recently still-general-purpose computing to the tasks of tilling, sowing, watering, weeding, spraying, and reaping.

Taking these two types of technology to characterize independent dimensions, then, we can demarcate four broad regions in which to situate possible agricultural operations (Figure 1). In the region of high environmental control but low electromechanical technology, we have operations like traditional greenhouses, which have been used for hundreds of years around the world without any electromechanical means for crop management. In the converse region, on the other hand, industrial grain agriculture operates in a less controlled outdoor environment subject to the vagaries of the weather, but uses increasingly sophisticated electromechanical means for management (e.g., self-driving tractors). Smart farms, as popularly conceived, appear to use both strict environmental control and sophisticated electromechanical means of crop/plant management.

\subsection{What Counts as a Smart Farm?}

We consider the distinctively smart aspect of a smart farm its combination of environmental control and heavy use of electromechanical technology. This is a reasonably precise characterization, but it still admits many possible concrete agricultural designs (just as both traditional greenhouses and espaliered fruit orchards are distinct instances of a high-control, low-tech design).

In what follows, we focus most intensely on a currently-popular form of smart farming: the so-called vertical farm. Such farms are indoor operations that stack rows of crops atop one another, each with its own light source, usually employing hydroponics rather than a soil medium. The vertical farm is a useful test case not only because of its exemplary environmental control and use of high technology, but also because it is a design which has several concrete instantiations, as startups around the US have built facilities and are selling produce $[6,30]$. After discussion of the vertical farm, we can move to considering less paradigmatic cases. (For example, the nascent practice of precision agriculture-using computers, sensors, and actuators to make small, efficient adjustments to traditional field crops-is a partial deployment of smart farm concepts.)

\section{ENERGY FLOWS}

Agriculture has always been an energy-harvesting technology, taking energy from the sun through plant photosynthesis for human use. The indoor smart farm, for the first time, breaks this fundamental concept at large scale. In its best form, powered by solar photovoltaics, it decouples the energy capture from the sun from plant growth, using artificial lighting (typically LEDs) to grow plants indoors at high density. The vertical nature of the growing arrangement requires this, as each level of plants would otherwise shade those below from illumination. However, this type of indoor growing presents fundamental and seldom-acknowledged problems for 


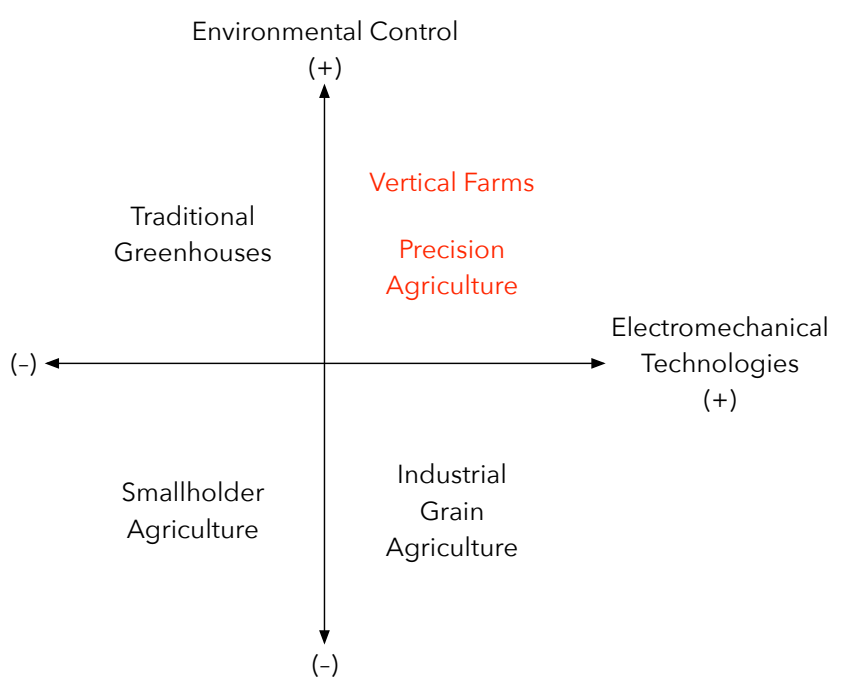

Figure 1: Design space of technologies for farming systems. (Farming systems listed are exemplary, not exhaustive.)

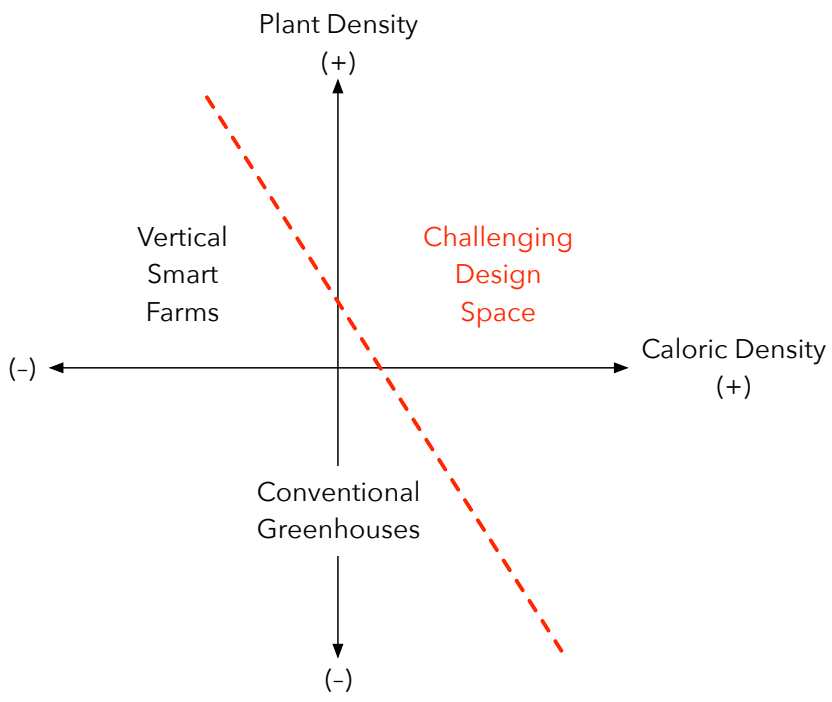

Figure 2: Design space of smart farm approaches. The design predicament for smart farm proponents is to create a system that can grow calorie-dense crops at high spatial density.

growing almost anything other than greens or herbs, described in greater detail below.

\subsection{Energy Transitions and Energy Loss}

Converting energy from one form to another necessarily incurs losses. In an indoor smart farm, electricity is needed to power banks of grow lights. In most areas of the world today, the vast majority of grid electricity is generated through fossil-fueled power plants. Such plants themselves are inefficient as they burn a fuel to boil water to turn a turbine. At each step in this process (fossil fuel combustion $\rightarrow$ water to steam $\rightarrow$ turbine rotation $\rightarrow$ electrical generation $\rightarrow$ transmission $\rightarrow$ electricity to light) there is energy loss, making indoor illumination of plants incredibly energy-inefficient relative to sunlight. Sustainability concerns should make us wary of organizing our food systems this way, even when the initial source of energy is solar PV or some other renewable technology. While such sources are less polluting than fossil fuel combustion, the same inefficiencies are baked in at every transducing step. Further, the estimates of energy requirements are most likely an underestimate due to energy requirements of the digital infrastructure necessary to run a smart farm [32].

\subsection{Calorie Crops and their Density}

Calorie-dense grains, vegetables, and fruits require large amounts of direct, intense light. Indoors, this is accomplished by arrays of powerful lamps, but operating the lamps generates so much heat that a separate cooling system is needed to keep the plants at an acceptable temperature when at high density. Thus growing calorie crops indoors is energy-intensive, which both counts against sustainability and also increases the monetary cost of the operation. As a result, growing calorie crops indoors makes economic sense only if their price premium is high enough to make a profit. But staple calorie crops such as potatoes fetch no such price. As a result, only crops with low light requirements, such as lettuce and other leafy greens, are economical to grow indoors, as we explore next. And indeed, this is exactly the business of urban vertical farm startups like Plenty [30] and Bowery [6]. But of course, leafy greens alone cannot feed the world.

While typically not conceived of in this manner, we find that a key commonality, rather than difference, between current approaches is that they inherently sacrifice on caloric density for plant density. As a result, they are increasingly not a viable approach to producing sustainable food that meets humanity's needs as the crops they support cannot meet the daily needs of an individual beyond providing supplemental micronutrients (Figure 2).

There are two major types of light sources that are used: fluorescent and LED. (LED is much more energy efficient, using approximately $60 \%$ of the energy). The goal of indoor production has been extensively studied [28], often in the context of producing crops in space [45]. In 2018 in a cost analysis showed that leafy greens were profitable, while vegetables (value $9.5 \%$ of cost) and grains (value $.01 \%$ of cost) lost large amounts of money when grown in an artificially lit environment [28]. There is also a difference in the cost per calorie produced: while it is easy to produce micro-greens, the number of calories produced is limited, and the more caloriedense vegetables and grains cannot be produced cost-effectively. Efficient LED lighting still does not provide a cost alternative to sunlight, for staple crops. Light remains the biggest impediment to most vertically farmed horticultural and grain crops, as it greatly increases the cost; this likely means that indoor farming is unlikely to be economically viable in the near future [4]. Indoor facilities can produce more per unit area, but this increase in production does not improve profitability or sustainability.

A related argument made for vertical farms is that they enable growing greens at this extremely high spatial density, and that the density alone is an advantage. However, this only takes into 
account fixed monocultural outdoor land as a point of comparison. If we instead take into account the Land Equivalent Ratio of greens grown as an understory beneath fruit trees, the density advantage vanishes: we should expect that there will be almost no yield loss for either the greens or the fruit trees, in effect gaining entirely free land upon which to grow greens.

Additionally, plants require a particular range of temperatures for optimal growth, and there is no standard way to heat and cool infrastructure built for greenhouses and other indoor growth facilities. Heating and cooling will have variable costs, depending on outdoor temperatures, and will also affect relative humidity and vapor pressure deficit inside the facility, variables that further affect plant growth. Of course, there are ways to compensate and modify intake and exhaust, as well as light quality (e.g. shade) to help modify plant transpiration, which affect productivity based on the outdoor conditions, but these too add to costs. Based on limitations of this kind, and contrary to the startup hype, it appears that leafy greens aren't merely the starting point for vertical farms-they are also its ending point.

\section{PRECISION AGRICULTURE}

When we move from the central exemplar of the smart farm-the indoor vertical farm-to less central cases, the natural "smart" practice to consider is so-called precision agriculture, which embraces computing and high-tech sensing, but retains conventional industrial agriculture's practice of growing plants outdoors, in the soil.

Precision agriculture has made great strides since the idea originated in the 1980s [21]. Much of the focus has been on optimizing the use of nutrients, usually focusing on minimizing the loss into the environment, through both in-field sensors to make real-time decisions and through remote sensing to retrospectively understand the impact of different decisions. This optimization has worked on targeted ways of managing the amount of nutrient or pesticide used, not in real-time measuring of plant deficiency then adding the required resource.

\subsection{Economic Concerns}

The cost of putting in-field or in-plant sensors to monitor exact plant conditions in a production field is currently difficult to do at scale, even with relatively small costs per field [20]. This is especially true for commodity crops; the size of farms (1000s of acres) makes the deployment of sensors difficult and capital-intensive, and requires large gains in order to justify the costs. This is especially important, as for many commodities, the margins are very small. In Minnesota in 2017, GM corn had a value of $\sim 1500$ USD per hectare with $\sim 400$ USD of profit, and organic corn had value of $\sim 2800$ USD per hectare with $\sim 800$ USD of profit; these margins are of course dependent on prices in a particular year [39]. Therefore to make economic sense, there must be a quick and immediate increase in value from any sensing system. Currently, there is limited evidence that the cost of implementing dense networks allows for improved decisionmaking in season, thereby leading to increased yields. Further, the maintenance of sensor networks requires significant labor, and thus increases the costs of using a network within the growing season. To date, adoption has occurred in high value crops (e.g., medicinal, vineyard), or in situations where the sensor information can be used to show proof of compliance with regulations.

\subsection{Data}

Work is being done to look at the minimum number of sensors needed to maximize gains. But in addition to this hardware problem, there is also a software and data problem: there is a large amount of proprietary data to be shared to train decision-making models, but a corresponding need for methods to be developed that can easily and quickly analyze data to create actionable items for farmers within season. There is some hope that satellite data could provide high enough spatial and temporal resolution to allow for real-time decision-making; however, such data is not available to farmers at present. The dream of precision agriculture as an outdoor smart farm, with heavy use of automation and machine-aided decision-making, is thus currently still just a dream. The reality of contemporary precision agriculture is twentieth-century industrial agriculture, plus a few gains in automation (e.g. driverless tractors).

\subsection{Limits}

Because current margins are small and rely on economies of scale in order to maintain profitability [13], there is a need for the new technology to improve the margins of large-scale farming. Sensors have improved this, but they add additional stresses on the system (e.g. e-waste-see Section 5) and, in some cases, increase net costs. In general, plant yield depends on the plants' ability to use light, soil nutrients and water to create biomass [12]. Thus narrow attempts to maximize efficiency (e.g., through precision irrigation) do not always lead to optimal overall outcomes for stakeholders or longterm sustainability. Identifying physiological limits of plants does not necessarily limit the ability of the land to produce high crop yields; what constitutes a good yield depends upon the values people have in different situations. Thus optimization for food production may be different from optimization for profit, which may be different still from optimization for ecological wellbeing. In fact, smallholders produce the majority of the world's food and often have higher productivity and sustainability than their largescale counterparts [36].

\subsection{Material Concerns}

One fact often overlooked by enthusiastic adopters of technology, perhaps because it is too mundane to notice, is that every new piece of technology is a new material object brought into the world. In industrial farming, for example, where draft animals have been supplanted by tractors, there is now the ubiquitous presence of large, expensive, fossil-fueled, decidedly non-biodegradable machines. Precision agriculture, like vertical farms run indoors, promises to continue increasing the number of manufactured objects on the farm-but the material nature of such technology comes with its own costs. It is to these costs that we now turn.

\section{MATERIALITY}

Computing technology has a physical footprint: the materials and energy used in its manufacture. As smart farms employ such technology at greater density than conventional farms do, the amount 
of manufactured-and thus, eventually, disposed-technology increases per unit of food produced. This is analogous to the way fossil fuels became commonplace in farming over the last century, to the point that each calorie of industrially produced food has a fossil fuel footprint an order of magnitude higher [31]. If smart farms become the norm, each unit of "smart" food will have a technology footprint, from e-waste and manufacturing embodied energy, far higher than in the past.

\subsection{E-waste}

Every piece of computing technology used in a smart farm is a material object with a finite lifespan, and at the end of its life becomes another piece of electronic waste [17, 43]. E-waste is well known to be hazardous [29], and proper disposal or recycling is expensive [38]. To the extent smart farms are billed as the "future of farming," we have to imagine this production of e-waste multiplied on a staggering scale.

Indoor smart farms are likely to employ a wide array of LED lights, sensors, pumps, actuators, cameras, and servers processing the data from these [34]. In high humidity environments such as greenhouses, such devices are likely to fail more frequently and thus require more frequent replacement. Purveyors of outdoor smart farming are considering soil sensors that are designed to fail in place after several years; even if the embodied energy of these devices is small relative to the caloric value of sunlight-driven production, they leave countless pieces of e-waste, with their embedded toxic components, to degrade in the soil.

\subsection{Embodied Energy}

Moreover, these material objects must be manufactured from raw material resources. The mining, processing, and manufacturing processes all have energy costs of their own; the sum total of such costs is the "embodied energy" of the manufactured object [8]. All the hardware that a smart farm employs carries an embodied energy cost not shared by conventional agriculture. Of course, conventional agricultural tools have their own embodied energy costs-but for smart farms to be sustainable, these costs are pressing, for it may well be the case that the embodied energy of the hardware exceeds the caloric value of the crops grown with that technology, especially for the non-calorie crops grown in a vertical farming / high-tech setup. ${ }^{1}$

Here we estimate the embodied energy cost of one aspect of vertical farming. Using available figures, we can easily estimate the per-plant embodied energy cost of LED illumination. One estimate of an $8 \mathrm{~W}$ LED lamp's manufacturing energy is $35.64 \mathrm{MJ}$ [25]. Using this figure, and an estimate of $600 \mathrm{~W}$ of lighting per square meter for growing greens [18] and an estimate of 47 plants per square meter [46], we arrive at an estimate of 75 LEDs per square meter, or $1.68 \mathrm{~W}$ LEDs per plant. Assuming a lifespan of 10 years for the LEDs (considering their environmental conditions and continuous use), and a 10-week harvest cycle per plant [14], each LED survives for 52 plant harvests, contributing 1.09 MJ of embodied energy cost to each head of lettuce. An average head of lettuce has 53 food

\footnotetext{
${ }^{1}$ Manufacturing processes do change over time and as such may improve in efficiency, but these changes are typically slow and unpredictable. For our calculations we use current figures.
}

calories, or $0.22 \mathrm{MJ}$-far less than the embodied energy of the LEDs used to grow it, let alone the electricity used for actual illumination or the energy of any other aspects of the vertical farm facility. This is a 5:1 loss on energy invested, considering only embodied energy costs of one farm component (i.e. far less than the total energy cost, which includes operating costs as well as the embodied energy costs of other components and the energy losses in electricity generation and transmission). Such an energy loss is clearly unsustainable. Perhaps in some circumstances this loss will come to seem worth it, on balance, but it is a strong prima facie reason to think that embodied energy considerations alone are enough to make vertical farming unsustainable.

\section{VALUES}

We now turn from practical questions about the smart farm's operation to normative questions about the values at stake more generally.

\subsection{Technologies Embody Value Systems}

In making some goal easier or faster to achieve than would otherwise be possible, technologies carry the implicit value judgment that accomplishing the goal is good, and that doing so faster or more easily is not only good, but is worth whatever costs the technology in question has. Thus we can ask: what value system does the smart farm embody?

The smart farm is an extension of automation and computing technology, applied to agriculture. As such, it further entrenches the values of standardization, centralization, abstraction, and control, and the elimination of human judgment, expertise, ecosystem functions, and labor. In effect, the smart farm is an automated factory, and its widgets are plants. This represents what is perhaps the apotheosis of the notion that a farm is "a factory in a remote area" [42]-but applying the kind of intense automation that changed the face of manufacturing in the 20th century, and creating the opportunity to bring the rural "factory" into the city.

With its streamlined conception of agriculture, the smart farm ignores many other values that have historically been part of agricultural production, and which might well be values we want to cultivate today-community, connection to the land, awareness of ecological relationships, and the distinctiveness of regional foods. To be clear, many of these values are already threatened or suppressed by globalization and conventional industrial farming. The smart farm is thus not unique, but rather the next stop along the trajectory from the industrial revolution to today's industrial agriculture, with all the attendant values and disvalues.

\subsection{Stakeholder Analysis}

One way to approach the question of the values a technology embodies is to ask: who has a stake in the implementation and operation of this technology? In the realm of value-sensitive design $[9,15,16]$, the method of stakeholder analysis explicitly considers this question.

6.2.1 Smallholder farming vs. vertical farms. In a striking and evocative example, the invention of the mechanical tomato harvester changed the face of tomato cultivation in 20th-Century California: it drastically reduced the number of tomato-growing operations 
(from about 4000 in 1960 to 600 in 1973), raised overall tomato production, eliminated tens of thousands of jobs, and introduced pressure to breed tomato varieties that would withstand being handled by machine-which breeders proceeded to do (famously at the cost of flavor) [44]. Because owning and operating the expensive machinery required large amounts of capital, very large growers benefited from its invention, and smaller growers suffered.

It is not difficult to take the tomato harvester as representative of agribusiness consolidation at large. Neither is it difficult to see the parallels to vertical farming: capital-intensive startup and operation costs, state-of-the-art technology, elimination of skilled human labor. If vertical farming operations continue to proliferate, we should expect to see a similar pattern of rewards, with large producers to benefit and small producers to be squeezed out.

And indeed, one particular consequence of the tomato harvester's invention-the breeding of new varieties that better suit the mechanical setting-appears to already be underway in the vertical farm sector. As of March 2021, the vertical-farming company AeroFarms is working with global berry producer Hortifrut to develop varieties of blueberries and cane berries that are better suited to indoor farm conditions [40]. (Whether this research will succeed-and how the berries will taste if it does-remains to be seen.)

6.2.2 Those affected by: mineral mining and e-waste. No technological system exists in a social vacuum, and smart farming will affect more people than simply those immediately involved in their operation, the people eating produce, or the entrepreneurs and venture capitalists for whom smart farming is a chance to make money. Each of these parties stands to benefit in some way from the implementation and success of smart farms. Yet other stakeholders stand to be harmed by smart farming, today and in the future. Today, the production and disposal of computing hardware creates burdens on specific groups of people, the most well-known being those affected by the mining of so-called conflict minerals in central Africa. But e-waste is also a dire pollutant, and the majority of e-waste generated in the US is shipped to developing nations, where it is dismantled without safety precautions, sent to a landfill, or burned-in any case, damaging the health of workers and polluting the local environment [24]. Then, of course, there are the future people of the planet, all of whom are harmed by today's unsustainable practices and climate pollution. These future stakeholders will not consider smart farming to be an improvement on conventional practices insofar as it continues to be a net polluter, and a net draw on resources.

\subsection{Business-as-Usual Values}

What the smart farm concept represents, as we think about it more generally, is the continuation of business as usual: capital-intensive agribusiness, crops grown in monoculture, ever-more-sophisticated computing technology presented as a "fix" or new paradigm but which is merely a refinement of existing practices, the creation of less resilient systems as we choose efficiency over resilience. The fact that smart farming is "more of the same" doesn't by itself show that smart farms can't be sustainable, but it should make us extremely wary of any promises from entrepreneurs or tech magazines that smart farms are the future of farming, or that they represent some new paradigm in growing food.

\section{OTHER CONSIDERATIONS}

\subsection{Disease and Pests}

The indoor smart farm design has two features that make it particularly susceptible to disease. First, the crops are grown as a monoculture-plots of plants of a single species. This is almost necessitated by the fact that the smart farm is to be automated (uniformity of plant habit, nutritional requirements, etc. is much easier for automated systems to handle). But monocultures are notoriously vulnerable to diseases, because pathogens tend to be species-specific, and once one plant becomes infected, the pathogen has easy access to more hosts. Second, the smart farm needs density to be economical-and of course crowding the plants only makes disease transmission worse.

These points apply as well to the crops' susceptibility to pests. Although indoor farms do in principle control what organisms are able to enter the system, such control is never complete, and pests may hitch a ride on workers or seeds, among other vectors. As such, the entry of pests is merely a matter of time: "Vertical farm operators should therefore be prepared for the eventuality of pest and/or pathogen access" [37].

\subsection{Hype vs. Reality}

In many recent smart farm efforts, public perception and promotion (i.e., "hype") has overtaken reality.

7.2.1 Vertical farms. In Section 3 we described the basic energy challenges faced by vertical farming, which entail that, far from feeding the world, vertical farms are at best able to produce leafy greens and herbs at a higher spatial density than conventional agriculturewhich, once the Land Equivalent Ratio of greens grown under tree crops is accounted for, may not even be an improvement in spatial density. Major vertical farming companies, including Plenty, Bowery, and Aerofarms, all have grandiose promissory language on their corporate websites (Plenty: "The Future of Modern Farming"Bowery: "It's time to reimagine farming from the ground up"AeroFarms: "We Are Transforming Agriculture"), yet curiously, and consistent with our analysis, none are offering much produce other than leafy greens and herbs.

7.2.2 MIT Open Ag. One variation on smart farming was the MIT Open Ag project, which promised "smart food computers". The aim was to create a device-like a miniature smart farm in a box-that could be programmed to grow an individual plant or group of plants given a specification of its needs. However, the technology itself was effectively the same as hydroponic approaches already well established and used by others, and as the technologists behind this effort found, it was easier to fake the results than to actually successfully grow plants in this manner [7].

7.2.3 Bespoke Berries. As described in Section 6.2.1, there is currently a private collaborative research effort to breed varieties of blueberries and cane berries that are optimized for indoor growing conditions, such that vertical farms can produce them efficiently. 
Press coverage of the announcement bears titles like "Vertical Farming Opens Doors To Fruit Growing” [40] (sounding conspicuously more ambitious than the actual plans). But our fundamental analysis of the vertical farm's predicament in the case of lettuce and other leafy greens-the energy requirements for illumination, the embodied energy of the farm technology, the economic challenge of making a profit on crops grown in this fashion-of course applies to berries as well, and is all the more pressing given that they are more calorie-dense crops. The embodied energy alone of the berries may be higher than their caloric value, not to mention the attendant externalities of the system, such as e-waste.

\subsection{Ultimate Goals}

When criticizing new technologies, we must always ask: are we just making the perfect the enemy of the good? In our view, systems do not need to be perfect, as all new technologies will have problems in their early years; and in any case the benefits of a technology are often worth whatever costs it has. However, it is crucial to make explicit the implicit assumptions of technological systems, for without doing so we cannot intelligently address the cost/benefit question. We also need to ensure, once a technology is implemented, that we have the ability to accurately determine whether the intended results are being obtained, and to identify ways of dealing with inevitable unintended consequences.

What do we want, ultimately, out of new agricultural technologies? Does the smart farm's cluster of technological suites serve our goals? There is no question that technologies like automation, highresolution images, cheap and accurate sensors, micro-environment modification, high-performance computing, and machine learning algorithms are useful. In particular, these technologies are of immense utility to basic plant science; small, controlled environments are providing an unprecedented ability to dissect molecular genetic pathways and to understand the interaction of micro-environmental properties with genotype (phenotypic plasticity)-but how to use this data at scale to make decisions that will impact agriculture is less clear. The data generated at field scale or through satellite imagery have been effective at generating retrospective models, or recapitulating data generated by conventional phenotyping, but have yet to produce many novel insights that increase the efficacy of selection. Two key exceptions to this are the characterization of genebanks where remote sensing could greatly increase knowledge [35], and the ability of remote sensing to improve accuracy of measurements [3]. There is also potential to reduce farm costs, particularly through reduction in labor. However, all of these uses, including even such speculative projections as robotics that harvest (e.g. in vineyards), envision merely making small efficiency improvements on current systems. But there is a wide area of agricultural systems to explore with present and future technology-abandoned systems and heretofore unimagined systems alike.

\section{FUTURE DIRECTIONS}

Smart farms may not be so smart after all-even by their own aims, they are unlikely to fundamentally alter the world's food system, or even contribute substantially to feeding people. By broader metrics, they embed questionable value systems, and risk aggravating the disparate social burdens of existing industrial agriculture, computing, and manufacturing.

Some alternatives already present themselves. Conventional industrial agriculture has its problems, of course, but it can be done using existing technology and infrastructure, and is at least not a further step in the direction of unsustainable systems. Passive greenhouse systems have much to recommend them, especially with thermal retention upgrades, and this form of agriculture has been pursued in China [10] among other places. Aquaponics-the simultaneous cultivation of fish and plants in a system that cooperatively cycles nutrients in a closed-loop system-mimics ecological relationships, conserves nutrients and resources, and can be done at large scale [26, 27]. And there is no reason why urban fruit walls cannot be redeployed today, perhaps especially in suburban areas [11].

In addition, there are alternative approaches to agriculture which do not rely on anything like the high-tech computing infrastructure of smart farming. For example, the Land Institute is researching perennial agriculture, and has developed several perennial crops, which do not require the annual costs of plowing, seeding, and spraying, and which also have improved soil retention [19]. Perennial crops are also important for permaculture and agroecology, related approaches to farming that aim to create ecologically resilient and long-lasting polycultures-groups of plants grown together to mutual benefit. Polycultures were present in the agriculture of traditional communities (as a famous example, the indigenous panAmerican cultivation of the Three Sisters: corn, beans, and squash), and are still practiced in traditional communities today.

All of these systems should be explored and, to the extent that they are effective and sustainable, implemented. Yet today society is demanding more and different things from agricultural systems. Beyond just food, fiber, and feed, we now want ecosystem services that include wildlife habitat, pollinator services, carbon sequestration, water quality maintenance, and soil conservation. Agricultural system planners need to think in a way that holistically addresses all the services that society desires, not marginally improve a system that fails to deliver all of these services (and in many ways works against them). Advances in data collection and analytic techniques provide a valuable opportunity to re-envision agriculture in ways that have never before been tried, that more closely mimic nature [12], or that maximize robotics and technical solutions. There is a need to combine computing and human action and desires into agriculture, but it should be done wisely, not "smart"ly.

In Figure 3 we consider the existence of an unexplored design space which could be a genuinely new frontier for agriculture: socio-technical systems which combine high agroecological complexity (as permaculture and agroecology aim to do) but which also integrate advanced computing and robotics [33]. The dimensions of relevance include the ways in which agricultural practices employ simple or complex agricultural ecosystems and their methods of labor automation. We believe that there is a largely-unexplored region of the design space in which highly ecologically complex agricultural systems are semi-autonomously managed.

\section{REFERENCES}

[1] Aero Farms. 2021. Aero Farms. https://aerofarms.com/ Accessed April 2, 2021. 


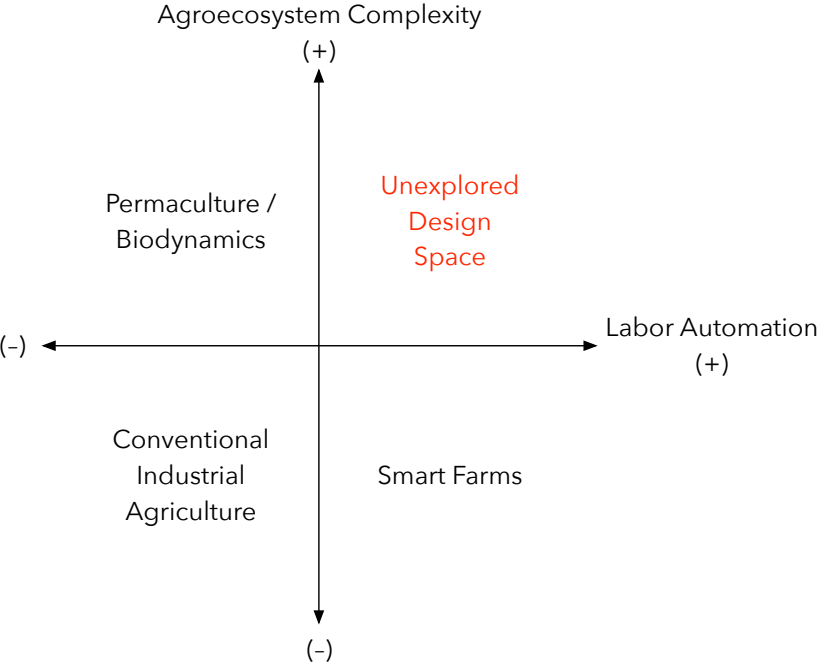

\section{Figure 3: Design space of farming systems from an agroeco- system point of view.}

[2] Andon Cord. 2017. Vertical Farming Startup Achieves "Plenty" with Less Water. https://digital.hbs.edu/platform-rctom/submission/vertical-farming-startupachieves-plenty-with-less-water/ Accessed April 2, 2021.

[3] José Luis Araus, Shawn C Kefauver, Mainassara Zaman-Allah, Mike S Olsen, and Jill E Cairns. 2018. Translating high-throughput phenotyping into genetic gain Trends in plant science 23, 5 (2018), 451-466.

[4] Senthold Asseng, Jose R Guarin, Mahadev Raman, Oscar Monje, Gregory Kiss, Dickson D Despommier, Forrest M Meggers, and Paul PG Gauthier. 2020. Wheat yield potential in controlled-environment vertical farms. Proceedings of the National Academy of Sciences 117, 32 (2020), 19131-19135.

[5] Matt Barnard. 2018. Can indoor farming feed the world? https://www.weforum org/agenda/2018/09/can-indoor-farming-feed-the-world/ Accessed April 5, 2021

[6] Bowery. 2020. https://boweryfarming.com/.

[7] Erin Brodwin. 2019. The Epstein-funded MIT lab has an ambitious project that purports to revolutionize agriculture. Insiders say it's mostly smoke and mirrors. https://www.businessinsider.com/mit-media-lab-personal-foodcomputers-dont-work-fake-staff-say-2019-9.

[8] Robert Costanza. 1980. Embodied energy and economic valuation. Science 210, 4475 (1980), 1219-1224.

[9] Janet Davis and Lisa P. Nathan. 2015. Value Sensitive Design: Applications, Adaptations, and Critiques. Springer Netherlands, Dordrecht, 11-40. https: //doi.org/10.1007/978-94-007-6970-0_3

[10] Kris De Decker. 2015. Reinventing the Greenhouse. Low-Tech Magazine (2015)

[11] Kris De Decker. 2016. Fruit Walls: Urban Farming in the 1600s. Low-Tech Magazine (2016).

[12] R Ford Denison. 2012. Darwinian agriculture: how understanding evolution can improve agriculture. Princeton University Press.

[13] Michael Duffy. 2009. Economies of size in production agriculture. Fournal of hunger \& environmental nutrition 4, 3-4 (2009), 375-392.

[14] Freight Farms. 2021. Vertical Farming in the Greenery S. https://www. freightfarms.com/blog/vertical-farming

[15] Batya Friedman, Peter H. Kahn, and Alan Borning. 2006. Value Sensitive Design and Information Systems. In The Handbook of Information and Computer Ethics. Wiley-Blackwell, 69-101. https://doi.org/10.1002/9780470281819.ch4

[16] Batya Friedman, Peter H. Kahn, Alan Borning, and Alina Huldtgren. 2013. Value Sensitive Design and Information Systems. Springer Netherlands, Dordrecht, 55-95. https://doi.org/10.1007/978-94-007-7844-3_4

[17] Elizabeth Grossman. 2007. High tech trash: Digital devices, hidden toxics, and human health. Island press.

[18] Horticoled. 2021. LED grow lights : How many are needed per square meter? https://www.horticoled.com/led-grow-lights-how-many-per-squaremeter/?lang=en

[19] The Land Institute. 2021. Perennial Crops: New Hardware for Agriculture. https: //landinstitute.org/our-work/perennial-crops/.

[20] Jirapond Muangprathub, Nathaphon Boonnam, Siriwan Kajornkasirat, Narongsak Lekbangpong, Apirat Wanichsombat, and Pichetwut Nillaor. 2019. IoT and agriculture data analysis for smart farm. Computers and electronics in agriculture
156 (2019), 467-474.

[21] David J Mulla. 2013. Twenty five years of remote sensing in precision agriculture: Key advances and remaining knowledge gaps. Biosystems engineering 114, 4 (2013), 358-371.

[22] NRDC. 2020. Industrial Agriculture 101. https://www.nrdc.org/stories/industrialagriculture- 101

[23] William Odom. 2010. Mate, we don't need a chip to tell us the soil's dry: opportunities for designing interactive systems to support urban food production. In Proceedings of the 8th ACM Conference on Designing Interactive Systems. ACM, 232-235.

[24] Oladele Ogunseitan. 2013. The Basel Convention and e-waste: Translation of scientific uncertainty to protective policy. The lancet global health 1 (12 2013), e313-e314. https://doi.org/10.1016/S2214-109X(13)70110-4

[25] OSRAM Group. 2021. Life cycle analysis of an OSRAM light-emitting diode lamp. https://www.osram-group.com/en/sustainability/environmental/productlifecycle-management/lca-led

[26] D. Allen Pattillo. 2017. An Overview of Aquaponic Systems: Aquaculture Components. NCRAC Technical Bulletins 20 (2017). http://lib.dr.iastate.edu/ncrac techbulletins $/ 20$

[27] D. Allen Pattillo. 2017. An Overview of Aquaponic Systems: Hydroponic Components. NCRAC Technical Bulletins 19 (2017). http://lib.dr.iastate.edu/ncrac techbulletins $/ 19$

[28] PM Pattison, JY Tsao, GC Brainard, and B Bugbee. 2018. LEDs for photons, physiology and food. Nature 563, 7732 (2018), 493-500.

[29] Devin N. Perkins, Marie-Noel Brune Drisse, Tapiwa Nxele, and Peter D. Sly. 2014. E-Waste: A Global Hazard. Annals of Global Health 80, 4 (2014), 286-295. https://doi.org/10.1016/j.aogh.2014.10.001

[30] Plenty. 2019. http://plenty.ag.

[31] Michael Pollan. 2008. Farmer in chief. New York Times Magazine 12 (2008).

[32] Chris Preist, Daniel Schien, and Eli Blevis. 2016. Understanding and Mitigating the Effects of Device and Cloud Service Design Decisions on the Environmental Footprint of Digital Infrastructure. In Proceedings of the 2016 CHI Conference on Human Factors in Computing Systems (San Jose, California, USA) (CHI '16). Association for Computing Machinery, New York, NY, USA, 1324âĂŞ1337. https: //doi.org/10.1145/2858036.2858378

[33] Barath Raghavan, Bonnie Nardi, Sarah T. Lovell, Juliet Norton, Bill Tomlinson, and Donald J. Patterson. 2016. Computational Agroecology: Sustainable Food Ecosystem Design. In Proceedings of ACM CHI alt.chi.

[34] Partha Pratim Ray. 2017. Internet of things for smart agriculture: Technologies, practices and future direction. Fournal of Ambient Intelligence and Smart Environments 9, 4 (2017), 395-420. https://doi.org/10.3233/AIS-170440 Publisher: IOS Press.

[35] GJ Rebetzke, J Jimenez-Berni, RA Fischer, DM Deery, and DJ Smith. 2019. Highthroughput phenotyping to enhance the use of crop genetic resources. Plant Science 282 (2019), 40-48.

[36] Vincent Ricciardi, Zia Mehrabi, Hannah Wittman, Dana James, and Navin Ramankutty. 2021. Higher yields and more biodiversity on smaller farms. Nature Sustainability (2021), 1-7.

[37] Joe Roberts, Toby Bruce, Jim Monaghan, Tom Pope, Simon Leather, and Andrew Beacham. 2020. Vertical farming systems bring new considerations for pest and disease Management. Annals of Applied Biology 176 (02 2020). https: //doi.org/10.1111/aab.12587

[38] Brett H. Robinson. 2009. E-waste: An assessment of global production and environmental impacts. Science of The Total Environment 408, 2 (2009), 183-191. https://doi.org/10.1016/j.scitotenv.2009.09.044

[39] Harpinder Sandhu, Nadia El-Hage Scialabba, Chris Warner, Fatemeh Behzadnejad, Kieran Keohane, Richard Houston, and Daniel Fujiwara. 2020. Evaluating the holistic costs and benefits of corn production systems in Minnesota, US. Scientific reports 10, 1 (2020), 1-12.

[40] MMW Staff. 2021. Vertical Farming Opens Doors To Fruit Growing. https://www. growingproduce.com/fruits/vertical-farming-opens-door-to-fruit-growing/.

[41] Kentaro Toyama. 2011. Technology as amplifier in international development. In Proceedings of the 2011 iConference. ACM, 75-82.

[42] Markwart von Pentz. 2016. Precision Farming's Global Future. https://www.dtnpf.com/go/agsummit/agsummit2016/presentations/mon_ gen_precision_farming_vonpentz.pdf.

[43] Rolf Widmer, Heidi Oswald-Krapf, Deepali Sinha-Khetriwal, Max Schnellmann, and Heinz Böni. 2005. Global perspectives on e-waste. Environmental impact assessment review 25, 5 (2005), 436-458.

[44] Langdon Winner. 1980. Do artifacts have politics? Daedalus (1980), 121-136.

[45] Naichia Yeh and Jen-Ping Chung. 2009. High-brightness LEDsâǍŤEnergy efficient lighting sources and their potential in indoor plant cultivation. Renewable and Sustainable Energy Reviews 13, 8 (2009), 2175-2180.

[46] Conrad Zeidler, Daniel Schubert, and Vincent Vrakking. 2017. Vertical Farm 2.0: Designing an Economically Feasible Vertical Farm - A combined European Endeavor for Sustainable Urban Agriculture. (01 2017). 